\title{
Dry batch anaerobic digestion of food waste in a box-type reactor system: Inoculum preparation and reactor performance.
}

\author{
Carlos Rico ${ }^{\mathrm{a},{ }^{*}, \text { Jesús A. Montes }}{ }^{\mathrm{a}}$, Amaya Lobo ${ }^{\mathrm{a}}$ \\ ${ }^{a}$ Department of Water and Environmental Science and Technologies, University of Cantabria, Avda. Los \\ Castros, s/n, 39005, Santander, Spain \\ * Corresponding author. Tel.: +34 942201848; fax: +34 942201703. \\ E-mail address: ricoc@unican.es (Carlos Rico)
}

\section{Abstract}

A box-type reactor system with liquid inoculum has been studied for the dry anaerobic digestion of food waste. The food waste was processed without any pre-treatment to remove physical impurities, neither water addition to dilute and slurry the feedstock. The experiment was carried out with inoculum to substrate ratios of 1:1 (w/w) and 0.08:1 (VS basis). Previous acclimation of liquid inoculum enhanced the process, assuring a fast start up of the box digester and preventing from process failure by volatile fatty acids accumulation. The percolate recirculation strategy was shown to have a relevant effect on the progress of the process. The results suggest that the process can be optimised by providing low percolate recirculation rate during the start-up of the box digester followed by an increase in the percolate recirculation rate when volatile fatty acids decrease and methane content in the biogas increases. The methane yield obtained in the box digester from the food waste was in the range $460-477 \mathrm{~L} \mathrm{CH}_{4} \mathrm{~kg}^{-1}$ VS, being the VS removal efficiency between 91.1 and 91.4\%. Globally, the process operated at an organic loading rate of $2.5 \mathrm{~kg} \mathrm{VS} \mathrm{m}^{-3} \mathrm{~d}^{-1}$ and yielded a volumetric methane production rate of $1.0 \mathrm{~m}^{3} \mathrm{CH}_{4} \mathrm{~m}^{3} \mathrm{~d}^{-1}$. These results show the high potential of 
food waste for its conversion in renewable energy by using the dry batch anaerobic technology.

Keywords: Biogas; Food waste; Garage digester; Liquid inoculum; Percolate recirculation; Waste to energy. 


\section{Introduction}

The socio-economic changes that have occurred in the last decades due to urban population increase, the development of the food industry and the rise of consumption trends, have resulted in an increase of the generation of food waste, particularly in areas of high population density. Food waste includes organic waste discharged from various sources such as food processing plants, domestic and commercial kitchens, cafeterias and restaurants (Yang et al., 2019). Food waste is also the largest fraction of municipal solid waste (Algapani et al., 2016). In the European Union, approximately 88 million tons of food waste are generated each year (Scherhaufer et al., 2018). Furthermore, about one-third of the food produced is wasted globally, which amounts to about 1.3 billion metric tons each year (Brunklaus et al., 2018).

Food waste is a problematic waste not only because of the huge amounts generated, but also because the broad range of environmental impacts that its management causes, such as water and air pollution, as well as greenhouse gas emissions (Schanes et al., 2018). Landfilling, the most used disposal method for food waste, contributes to the release of high organic load leachates and greenhouse gases. Indeed, reducing and diverting this waste in landfills has become a priority, especially considering the negative impact of food waste on global climate change and associated environmental challenges (Morone et al., 2019). Currently, the amount of biowaste landfilled is restricted in the European Union by the European Council Directive on the landfill of waste (Council Directive 1999/31/EC).

Anaerobic digestion is one of the biological treatments for organic waste that is receiving increasing attention due to its high valorisation value for waste (Bong et al., 
2018). The characteristics of food waste match the needs for the anaerobic digestion process because it presents high biodegradability and high volatile solids (VS) content (Edwiges et al., 2018; Fisgativa et al., 2016). Moreover, anaerobic digestion of food waste not only provides renewable energy, but also promotes nutrient recovery in the digestate, which can be used as biofertilizer (Koido et al., 2018). Therefore, anaerobic digestion of food waste offers opportunities for energy recovery and nutrient reclamation because it requires less space and input energy to operate than landfilling, composting and incineration (Ventura et al., 2014). Furthermore, anaerobic digestion can mitigate greenhouse gases emissions since biogas is regarded as a climate-neutral fuel (Reinelt et al., 2017).

Anaerobic digestion can be performed at wet or dry conditions. The total solid (TS) content of the feedstock is the parameter that differentiates both type of operations. It has been assumed that the line separating wet and dry digestion modes is $15 \%$ TS (André et al., 2018; Di Maria et al., 2017). Thus, in wet processes for solid waste, the feedstock has to be slurried with the addition of water, reducing the TS below 15\%, which reduces the energy density of the waste and increases the consumption of energy and water. This procedure creates a pumpable slurry that is processed using the completely stirred tank reactor technology (Angelonidi et al., 2015). On the contrary, dry digestion offers some technical advantages, including facilitation of the high-solids substrate manipulation, greater flexibility in the type of feedstock accepted, reduced volume of reactors, and more flexible management (Angelonidi et al., 2015; Braguglia et al., 2018).

Although wet operation mode is the most common form for anaerobic digestion, there is an increasing interest in dry anaerobic digestion technology (Braguglia et al., 2018). 
Amongst the different dry anaerobic digestion technologies, the batch mode process in digestion boxes with percolate recirculation is increasingly common, but can still be considered an emerging technology, especially in terms of diffusion (Chiumenti et al., 2018). This dry anaerobic reactor system process is called garage-type due to the esthetical similarity of the digester box with a long barn or a garage. A key benefit of this technology is that the feedstock remains stationary in the box compartment, so that no moving parts (stirring devices) are required, resulting in low energy consumption (Chiumenti et al., 2018; Qian et al., 2017). This way of operation also makes the process very tolerant for physical impurities (stones, bones, glass, sand or rests of plastic bags) that can be found in solid biowastes. These impurities can lead to plant malfunctions, increased equipment wear or pipe clogging in wet anaerobic digestion as a result of an insufficient pretreatment or impurities separation (Di Maria et al., 2017; Jank et al., 2017).

The box-type anaerobic system can be seeded with solid or liquid inoculum and the process is commanded by the recirculation of the percolate, which is sprinkled over the feedstock. It makes necessary an external storage tank for the percolate. The recirculation of the percolate enhances the contact between substrate and microorganisms, increasing the moisture of the substrate and washing out the solubilized organic matter to the percolate tank, which works as a methanogenic reactor. Increasing the relative amount of inoculum will make the process more stable and able to reach higher methane yields, but also less competitive in terms of investment costs due to unnecessarily increased digester size (Chanakya et al., 1997; Di Maria et al., 2012). Reactor inoculation with solid digestate leads to a loss in the volume capacity of the reactor (Pognani et al., 2015; Qian et al., 2017) whereas the use of liquid inoculum 
requires a percolate tank with increased size. Comparable methane yields have been reached through liquid and solid inoculation as described by Qian et al. (2017).

The relative amount of inoculum and the percolate recirculation strategy are presumably critical factors in dry batch anaerobic digestion of food waste because the rapid production of volatile fatty acids through the fermentation can lead to process failure (Li et al., 2018). When percolate is sprinkled over the substrate to initiate the process, an excessive high rate of percolate recirculation can lead to acidification of the process (Degueurce et al., 2016), inhibiting the process by volatile fatty acids accumulation and low $\mathrm{pH}$. In contrast, a low rate of percolate recirculation slows down the process, making it less competitive. Thus, percolate recirculation must be optimized to get the best process performance. In wet systems for anaerobic digestion of food waste, some authors have suggested two-stage process as beneficial because separation of hydrolysis/acidogenesis from methanogenesis enhances the stability of the process and protects methanogens from rapid acidification (Li et al., 2018; Shen et al., 2013). In this sense, the box-type reactor system performs as a hybrid process where methanization occurs in the box compartment and in the percolate tank (Di Maria et al., 2017).

The objective of this research is to investigate the dry batch anaerobic digestion of food waste in box-type reactor system using liquid inoculum. A lack of information about conditions of maturation and acclimation of liquid inoculum in dry batch anaerobic digestion has been reported (André et al., 2018). The preparation of the liquid inoculum from liquid dairy manure and the operation of box-type digesters with non-pretreated food waste as feedstock to study the technical feasibility of the engineered process were investigated. The percolate recirculation strategy as a key parameter to optimize the performance of the box-type process was analysed. 


\section{Materials and methods}

\subsection{Food waste}

Food waste (FW) was collected from two cafeterias close to the Civil Engineering School in the University of Cantabria. FW was source separated and consisted of different proportions of potato peeling and rests of bread, vegetables and fruits, meat, fish and paella (rice). The FW was collected on three occasions. The first two times FW was used for the cultivation of the inoculum, whereas the third time FW was used for the operation of the box-type digesters. The FW was digested without any pre-treatment like reducing particle size or crushing. A description of FW components and main characteristics of each lot are summarized in Table 1.

\subsection{Inoculum cultivation}

Screened liquid fraction of dairy manure was used as inoculum source. It was first digested alone in the box digesters to promote the growth of the microorganisms and the degradation of the biodegradable organic matter in the original manure slurry. Later, the digested liquid manure was acclimated by two consecutive anaerobic digestion batch processes with FW. These batches were carried out by flooding in the box digester. After FW flooding digestion process, the liquid inoculum was screened through a $1 \mathrm{~mm}$ mesh sieve to remove big size solids. Mesophilic temperature range was selected for the process because of the high ammonia nitrogen concentration expected from the liquid manure used as inoculum and from the FW used as feedstock, which is a substrate with a typical low C/N ratio (Capson-Tojo et al., 2016).

\subsection{Box digesters}


Two box-type reactor systems (BTRS) made of 304 stainless steel were used. Each BTRS consists of two separate compartments, one of them being for the feedstock (box tank) and the other one for the liquid inoculum (percolate tank). The box compartment is $25 \mathrm{~cm}$ wide, $50 \mathrm{~cm}$ long and $25 \mathrm{~cm}$ high, with a volume of $31.2 \mathrm{~L}$ (21.0 L of useful volume). The bottom has a $1.5 \%$ slope to facilitate percolate drainage and the compartment is provided with a physical barrier to contain the solid feedstock. The physical barrier has several openings at the bottom to allow the flow of the percolate. The sprinkler system consists in three perforated pipes in parallel. The percolate tank is $25 \mathrm{~cm}$ wide, $25 \mathrm{~cm}$ long and $23.5 \mathrm{~cm}$ high, provided with a conical bottom, having a volume of $16 \mathrm{~L}$ (12 L of useful volume). The box and the percolate tanks were constructed with the indicated size in such a way that in the case of needing a higher or lower liquid inoculum to feedstock ratio, both the tanks could be filled with variable amounts of both materials.

Both the compartments are equipped with temperature sensors (bimetallic thermometer, $15 \mathrm{~cm}$ stem length, $0-80^{\circ} \mathrm{C}$ ). A stable temperature of $36-38^{\circ} \mathrm{C}$ was maintained in the BTRS with thermostat-controlled electric heating blankets that covered the external walls and floor of the box tank and the external walls of the percolate tank. Percolate recirculation is carried out by a time controlled peristaltic pump, in cycles of one minute, which was set to pump an instant flow of $2 \mathrm{~L} \mathrm{~min}^{-1}$. Biogas produced in the box compartment and in the percolate tank were collected separately in gas bags and their volumes were measured by connecting the gas bag to a liquid displacement system device. The separate collection of the biogas coming from the box and the percolate tanks allowed a separate monitoring of the biogas production and quality from both the 
compartments. A scheme of the experimental dry batch digestion process is shown in Fig. 1.

\subsection{Mode of operation}

\subsubsection{Inoculum cultivation}

The liquid inoculum was acclimated by flooding FW with screened and digested liquid manure in the box compartment. This operation was carried out by two consecutive batches in order to check the acclimation of the inoculum. In these operations, $2.5 \mathrm{~kg}$ of FW (characteristics in Table 1) were flooded with $25 \mathrm{~L}$ of screened and digested liquid manure. This ratio provided an inoculum to substrate ratio (I/S) of 0.45 and 0.52 in terms of VS for batch 1 and batch 2, respectively. The batches were stopped when both, daily biogas production and volatile fatty acids concentration were negligible. Inoculum cultivation was monitored by biogas production and methane content in the biogas, $\mathrm{pH}$, alkalinity and VFA in the medium.

\subsubsection{Operation in box digesters}

The experiments of dry batch anaerobic digestion in the BTRS were performed in two different runs (R1 and R2). Each BTRS was loaded manually with $10 \mathrm{~kg}$ of FW (characteristics in Table 1) in the box tank and $10 \mathrm{~L}$ of liquid inoculum in the percolate tank. The feedstock was stacked avoiding tightening and compressing it in the box compartment. The difference between both runs was the percolate recirculation rate. The reactors were not flushed with any gas, so that the headspace of the reactors were initially composed by air. The objective was to compare BTRS operation with quite different percolate recirculation rates during the first middle part of the operation and the effect of increasing percolate recirculation rate at the second half of the operation. In 
R1, the percolate pump was programmed to work 6 minutes a day (1 recirculation operation each 4 hours), giving a daily recirculation volume to total percolate volume of 1.2. The percolate recirculation rate was doubled after 20 days, passing to 12 minutes a day (1 recirculation operation each 2 hours), giving a daily recirculation volume to total percolate volume of 2.4. In R2, the percolate pump was programmed to work 1 minute a day ( 1 recirculation operation each 24 hours), giving a daily recirculation volume to total percolate volume of 0.2 . The percolate recirculation rate was increased up to 12 minutes a day (1 recirculation operation each 2 hours) after 18 days, giving a daily recirculation volume to total percolate volume of 2.4. The increase in the percolate recirculation rate after the start-up of the process was planned to study their effect on biogas production rate once the process is running. The percolate recirculation strategy (rates and cycles) in Runs 1 and 2 during box digester operation have been summarized in Table 2.

\subsection{Analytical techniques}

The volatile fatty acids (VFA) were determined using a HP6890 gas chromatograph (GC) fitted with a $2 \mathrm{~m}$ 1/8-in glass column, liquid phase 10\% AT 1000, packed with the solid-support Chromosorb W-AW 80/100 mesh. Nitrogen was used as the carrier gas at a flow rate of $14 \mathrm{~mL} / \mathrm{min}$, and a FID detector was installed. The VFA concentration is expressed in Chemical Oxygen Demand (COD) units. The biogas composition was assayed on a 2 m Poropak T column in a HP 6890 GC system with helium as the carrier gas at a flow rate of $15 \mathrm{~mL} / \mathrm{min}$ with a TCD detector. The biogas and methane production measurements are expressed at $0^{\circ} \mathrm{C}$ and standard pressure of $760 \mathrm{~mm} \mathrm{Hg}$ in dry conditions. The $\mathrm{pH}$ was measured from samples with a glass electrode $\mathrm{pH}$ meter (WTW, SENTIX 21). Total Solids (TS), Volatile Solids (VS), Total Kjeldahl Nitrogen 
(TKN), Total Ammonia Nitrogen (TAN), Total Phosphorous (TP) and alkalinity were performed according to Standard Methods (APHA, 1998).

\section{Results and discussion}

\subsection{Inoculum acclimation}

Before the acclimation process, the digested liquid manure had the following characteristics: $2.30 \%$ TS, $1.41 \%$ VS, 3.3 g TKN-N L-1, 1.6 g TAN L-1, 8,900 mg $\mathrm{CaCO}_{3} \mathrm{~L}^{-1}$ alkalinity and a $\mathrm{pH}$ of 8.0. The operational parameters of the inoculum acclimation stage are depicted in Fig. 2. The FW in the first batch consisted of a 60/40 mixture of rests of bread and potato peel, having TS and VS content of 32.5\% and $30.6 \%$ respectively. The first batch followed a rapid acidification, with a drop in $\mathrm{pH}$ values to 6.9 (Fig. 2d) and an increase in VFA concentration that reached a peak of 18.6 g CODVFA $L^{-1}$ after seven days of operation, being acetic, propionic and butyric the predominant VFA (Fig. 2c). This acidification was overcome by the high alkalinity available in the medium (Fig. 2d), provided by the digested liquid manure, which allowed to recover the $\mathrm{pH}$ values and the subsequent degradation of the VFA. Biogas production started at the first operation day, but with a poor methane content in the first three operation days. The methane content in the biogas increased with time but required seven days to reach $50 \%$ (Fig. 2a). Subsequently, as VFA were consumed, methane content in the biogas increased up to values in a range between $65-70 \%$. The daily methane yield followed the typical curve of an anaerobic batch process (Fig. 2b), characterized by a peak in daily methane production rate that depends in extension and time on the substrate and inoculum characteristics and its ratio. The peak in methane production rate corresponds with a maximum daily specific methane yield of $34.7 \mathrm{~L}$ 
$\mathrm{CH}_{4} \mathrm{~kg}^{-1} \mathrm{VS} \mathrm{d}^{-1}$. After the peak, the daily methane yield started to drop as organic matter in the FW was consumed by the microorganisms. Biogas production was negligible after 25 days of operation. The cumulative production of methane was $310 \mathrm{~L}$ $\mathrm{CH}_{4}$, which corresponds with methane yields of $405 \mathrm{~L} \mathrm{CH}_{4} \mathrm{~kg}^{-1} \mathrm{VS}$ and $124 \mathrm{~L} \mathrm{CH}_{4} \mathrm{~kg}^{-1}$ fresh matter of FW. After the first acclimation batch, the $\mathrm{pH}$ of the liquid inoculum was 7.9, the alkalinity increased to $10,700 \mathrm{mg} \mathrm{CaCO}_{3} \mathrm{~L}^{-1}$ and the TAN was $1.98 \mathrm{~g} \mathrm{~L}^{-1}$. The increase in TAN concentration was caused by the hydrolysis of proteins contained in the FW.

The second batch showed an improvement in the performance of the inoculum. The peak in biogas and methane production occurred on the first operation day and the process only required two days to reach $50 \%$ methane content in the biogas. After seven days of operation, the methane content in the biogas reached $70 \%$. The rapid production of VFA (peak of $15.0 \mathrm{~g}_{\text {COD }} \mathrm{VFA}^{-1}$ after one operation day) did not bring a big drop in the $\mathrm{pH}$, and after four operation days the $\mathrm{pH}$ was in a value of 7.6. All the parameters of the process improved in the second batch, showing a good acclimation of the inoculum to the FW. For instance, the peak in daily specific methane yield was $46.7 \mathrm{~L} \mathrm{CH}_{4} \mathrm{~kg}^{-1}$ $\mathrm{VS} \mathrm{d}^{-1}$, which was $35 \%$ higher than that of previous batch. The cumulative methane production of the second FW batch was $366 \mathrm{~L} \mathrm{CH}_{4}$, resulting in methane yields of 542 $\mathrm{L} \mathrm{CH}_{4} \mathrm{~kg}^{-1} \mathrm{VS}$ and $146 \mathrm{~L} \mathrm{CH}_{4} \mathrm{~kg}^{-1}$ fresh matter. The higher methane yield compared with the previous batch can be attributed to the different composition of the feedstock. The presence of meat and fish in the second batch, with higher lipids content than those of bread and potato peel (Braguglia et al., 2018), justifies the higher methane yield obtained. The methane yield values obtained in the acclimation stage (405-542 $\mathrm{L} \mathrm{CH}_{4}$ $\mathrm{kg}^{-1} \mathrm{VS}$ ) are consistent with other results that can be found in the literature for FW with 
similar characteristics. Zhang et al. (2013) and Browne and Murphy (2013) reported methane yield values between 410 and $529 \mathrm{~L} \mathrm{CH}_{4} \mathrm{~kg}^{-1}$ VS for canteen FW. After acclimation process, the liquid acclimated inoculum had the following characteristics: 2.18\% TS, 1.22\% VS, pH of 8.0, alkalinity 12,100 $\mathrm{mg} \mathrm{CaCO}_{3} \mathrm{~L}^{-1}$ and TAN $2.60 \mathrm{~g} \mathrm{~L}^{-1}$.

The literature has reported different thresholds for ammonia inhibition in anaerobic digestion and a wide range of TAN inhibitory concentrations (1.7-14 g TAN L ${ }^{-1}$ ) can be found (Chen et al., 2008). In the study performed by Ariunbaatar et al. (2015), a TAN concentration of $3.8 \mathrm{~g} \mathrm{~L}^{-1}$ was reported as $50 \%$ inhibitory concentration of total ammonia nitrogen for their specific study (inoculum and substrate) on the anaerobic digestion of FW. Despite a high TAN concentration in the medium is susceptible to promote methanogenic inhibition, one of the effects of this kind of inhibition is the accumulation of propionic acid (Angelidaki et al., 1993). Thus, the total removal of VFAs during the two-acclimation batches is indicative of the absence or minimum effect of ammonia inhibition in the process.

\subsection{Dry batch operation in box digesters}

As previously stated, the experiment was performed in two different runs. Both BTRS were filled with $10 \mathrm{~kg}$ of non-pretreated FW (FW density of $0.67 \mathrm{~kg} \mathrm{~L}^{-1}$ ) and $10 \mathrm{~L}$ of liquid inoculum, which represents an initial I/S ratio of 0.08 . The BTRS operation was planned to be stopped when VFA were totally removed in the percolate. Qian et al. (2017) operated successfully a vertical leaching bed reactor with an I/S ratio of 0.17 (VS basis) for the dry batch anaerobic co-digestion of organic fraction of municipal solid waste and corn straw with liquid inoculum. Given the previous acclimation of the 
inoculum and that a higher I/S ratio would imply a much higher percolate tank size, the above mentioned I/S ratio (0.08) was applied.

\subsubsection{Biogas and methane production}

The BTRS produced biogas from the first operation day and was stopped when negligible VFA concentration in the percolates were observed, which occurred after 47 days of operation. The previous inoculum acclimation stage enhanced the start-up of the process and no lag-phase was observed in any of the runs. In a similar study, Qian et al. (2017) observed a 7 days lag-phase in a similar study. Cumulative biogas and methane yields of the experiments R1 and R2 are shown in Figs. 3a and 3b. During the first 15 operation days, biogas and methane were mainly produced in the percolate tanks. The BTRS produced specific methane yields of 477 (R1) and 460 (R2) $\mathrm{L} \mathrm{CH}_{4} \mathrm{~kg}^{-1}$ VS after 47 days. It is noteworthy that $71 \%$ (R1) and 70\% (R2) of the overall methane production came from the percolate tanks. Qian et al. (2016) reported a contribution of $60 \%$ of the total methane production in the percolate tank for an industrial scale garagetype facility for the treatment of MSW. The relative bigger size of the percolate tank in this case justifies this small difference. The biogas produced in the percolate tanks was also more methane-rich than that in the box compartments (Figs. 3c and 3d). Biogas from percolate tanks required $6(\mathrm{R} 1)$ and 5 (R2) days to reach 50\% methane content. After 12 (R1) and 9 (R2) days the methane content in the percolate biogas reached 70\%. Moreover, the low percolate recirculation rate in $\mathrm{R} 2$ resulted in maximum percolate biogas methane content, close to $80 \%$ after ten days of operation. On the other hand, biogas from box tanks required 17 (R1) and 23 (R2) days to reach 50\% methane content. The higher percolate recirculation rate in $\mathrm{R} 1$ produced a box tank biogas with more methane content. Despite the low methane content in the biogas coming from box 
compartments in the first operation days, its small contribution to the overall biogas production allowed to obtain an overall methane content higher than $50 \%$ in 8 (R1) and 7 (R2) days of operation.

\subsubsection{Influence of percolate recirculation rate on methane yield rate and VFA in the percolate}

The percolate recirculation strategy affected the rate of the process. The development of the process in terms of daily methane production rate (Figs. 3e and 3f) was characterised by the typical curve of a batch process (progressive increase in the daily methane production - peak - progressive decrease in methane yield values that ends in residual methane yield values). This trend in methane yield rate was clear for experiment R1, reaching a maximum peak of $36.3 \mathrm{~L} \mathrm{CH}_{4} \mathrm{~kg}^{-1} \mathrm{VS} \mathrm{d}^{-1}$ after 17 days, as can be observed in Fig. 3c. The experiment R2 followed the same trend with a smaller peak in daily methane yield values, consequence of the lower percolate recirculation rate. The peak in daily methane production rate for $\mathrm{R} 2$ was $20.6 \mathrm{~L} \mathrm{CH}_{4} \mathrm{~kg}^{-1} \mathrm{VS} \mathrm{d}^{-1}$ and took place at day 11 of operation. These peak values are higher than others previously reported in the literature for dry batch anaerobic digestion of organic wastes: 12.5 (Di Maria et al., 2017), 7.2 (Qian et al., 2016), 8.5 (Degueurce et al., 2016), 20 (Aymerich et al., 2013) $\mathrm{L} \mathrm{CH}_{4} \mathrm{~kg}^{-1} \mathrm{VS} \mathrm{d}^{-1}$. In any case, such comparisons must take into account the specific context of each work (substrate, inoculum, I/S ratio and percolate recirculation rate). The percolate recirculation was 12-time increased in R2 after 18 days to check the influence in daily methane yield. The result was an increase in daily methane yield and a second peak in methane production rate, which confirms the role of percolate recirculation rate in the progress of the process. The percolate recirculation rate was also increased in R1 after 20 days (when methane production rate was falling 
down), but in this case the effect in daily methane yield was minimal. It can be explained by the fact that the major part of the particulate organic matter in the FW had already been solubilized and transferred to the percolate tank.

Evolution of percolate VFA concentration during BTRS operation is depicted in Figs. 4a and 4b. The VFA concentration increased rapidly in both the percolates which indicates the suitability of the BTRS to promote the hydrolytic and acidogenic stages. The VFA concentration reached a peak that took place on day 7 of operation in both the reactors. The higher concentration of VFA in the $\mathrm{R} 1$ percolate can only be attributed to the higher percolate recirculation rate in R1, resulting in a peak of $40.1 \mathrm{~g} \mathrm{CODVFA}^{-1}$, with butyric acid being the principal VFA having a concentration of 19.3 g COD butyric $\mathrm{L}^{-}$ ${ }^{1}$ (Fig. 4a). On the other hand, the peak of VFA in R2 reached a value of 24.6 g CODVFA $\mathrm{L}^{-1}$ (Fig. 4b). Butyric acid was the predominant VFA in both the reactors for the first 10 days in R1 and for the first 5 days in R2. Afterwards, acetic was the predominant VFA in both the reactors. A similar VFA profile was reported by Xu et al. (2012), who observed butyric and acetic as the dominant VFAs in their study about hydrolysis and acidification of FW in a leaching bed reactor. When acetic was consumed, the only VFA remaining in the percolate was the propionic. Conversion of acetic and butyric acids into propionic acid has been attributed to a change in the dominant microbial population as the $\mathrm{pH}$ increases (Hawkes et al., 2002). The main process parameters during box digester operation have been summarized in Table 3.

Previous studies have indicated that a fast acidification with accumulation of VFA can lead to process failure in the solid-phase anaerobic digestion of FW. Li et al. (2018) reported the failure of the anaerobic digestion of FW after two operation days due to VFA accumulation and a pH drop to a value of 4.3. Jiang et al. (2018) reported a 
threshold inhibition concentration of $16.5-18.0 \mathrm{~g} \mathrm{VFA} \mathrm{L}^{-1}$ in the anaerobic co-digestion of FW and pig manure. Moreover, Zhang et al. (2015) reported severe inhibition at a VFA concentration of $30 \mathrm{~g} \mathrm{VFA} \mathrm{L}^{-1}$ in the anaerobic digestion of FW that was overcome with the addition of trace elements. Qian et al (2017) also observed VFA accumulation (18 $\left.\mathrm{g} \mathrm{L}^{-1}\right)$ accompanied with a drop in the $\mathrm{pH}$ down to 5.7 that ended in process failure at a daily recirculation volume to total percolate volume of 4.8 . In this regard, the previous acclimation of the inoculum and the high alkalinity available in the percolate in the present work allowed to prevent a big drop in $\mathrm{pH}$ (Figs. 4c and 4d) and the failure of the process.

The relation between percolate VFA concentration and daily methane yield can be useful to optimize the percolate recirculation strategy. The daily methane yield in R2 was higher than that in R1 up to day 11 (Fig. 5a). This circumstance concurs with the highest VFA concentration levels observed in R1 (Fig. 4a). This suggests that R1 was on a partial inhibition state due to the VFA concentration above 30 g CODVFA $L^{-1}$. The fast methane production started in both experiments when butyric acid concentration started to decrease, which took place first in R2 due to the lower levels of VFA in the percolate. Qian et al. (2017) observed a similar behaviour. The contribution of 5-day periods to the total methane yield clearly indicates the better performance of R2 compared to R1 in the time range of 5-10 days (Fig. 5b), which coincides with the high levels of VFA in R1. Thus, the process was enhanced by low percolate recirculation rate at the beginning of the process, which is in accordance with the suggestion of low percolate recirculation rates when initiating the process for optimal conditions for methanogens (Vavilin et al., 2003). However, the low percolate recirculation rate slowed down the progress in methane production in R2 between days 10 and 20 . 
Moreover, the high percolate recirculation rate in R1 allowed to yield more than $50 \%$ of the overall methane production between days 10 and 20, which gives evidence of the positive effect of increasing percolate recirculation as the process and the daily methane yield progress.

\subsection{3 pH, alkalinity and TAN in percolate}

The evolution of pH, alkalinity and TAN in percolates of R1 and R2 is shown in Figs. 4c and 4d. With the start of the process, the percolate $\mathrm{pH}$ decreased from an initial value of 8.0 to minimum values of 6.3 (R1) and 6.9 (R2) in the first five days of operation. The high alkalinity in the liquid inoculum avoided bigger drops in $\mathrm{pH}$ that could have caused inhibition as the recommended $\mathrm{pH}$ values for methanogens are within the range 6.5-7.5 (Kusch, 2012). Similar to VFA evolution, the higher hydrolysis and acidogenesis promoted by the higher percolate recirculation rates in R1 resulted in lower $\mathrm{pH}$ values. Part of the initial alkalinity content was consumed to keep the $\mathrm{pH}$ in safe values. Thus, from an initial alkalinity value of $12,600 \mathrm{mg} \mathrm{CaCO} \mathrm{L} \mathrm{L}^{-1}$ minimum values of 6,700 mg CaCO $3 \mathrm{~L}^{-1}(\mathrm{R} 1)$ and 7,500 $\mathrm{mg} \mathrm{CaCO}_{3} \mathrm{~L}^{-1}$ (R2) were observed in the first operation days. As VFAs were consumed, the $\mathrm{pH}$ and alkalinity rapidly recovered to their initial values. The TAN concentration in both the BTRS (Figs. 4c and 4d) remained in similar values to that of the initial TAN concentration of the liquid inoculum. The effect of protein hydrolysis of FW was counteracted by the large amount of moisture in the residue that augmented the volume of liquid percolate resulting in final percolate TAN concentrations of 2.4 (R1) and 2.6 (R2) g TAN L ${ }^{-1}$.

The results obtained confirms the benefit of increasing the percolate recirculation rate as the process progresses. The BTRS operation carried out could have been more efficient 
with a percolate recirculation strategy that combined the low recirculation rates of R2 at the beginning of the process and the higher rates of R1 between days 5 and 10 . The question about when the percolate recirculation must be increased and in what extent does not have a precise answer. However, the evolution of $\mathrm{pH}$, VFA and daily methane yield can be interpreted as a signal for correct decision-making on the percolate recirculation strategy. It is also presumable that the best percolate recirculation strategy will depend on the type of waste processed, and the quality and the amount of the inoculum.

\subsubsection{Mass balance of the BTRS}

The mass balance of the process is detailed in Table 2 for R1 and R2. The great VS and mass reduction from initial FW to solid digestate is noteworthy. Solid digestate showed lower moisture content than fresh food waste: $25.1 \%$ TS, $8.5 \%$ VS (R1) and 30.7\% TS, 8.7\% VS (R2). The VS removal percentage achieved was $91.4 \%$ in R1 and $91.1 \%$ in R2. In addition, the initial $10 \mathrm{~kg}$ of FW were reduced to 1.56 (R1) and 1.52 (R2) $\mathrm{kg}$ of solid digestate. The high moisture content of the initial FW resulted in an increase in the volume of percolate from $10 \mathrm{~L}$ to 16.3 (R1) and $16.4 \mathrm{~L}(\mathrm{R} 2)$.

\subsubsection{Technical implications}

One of the objectives of the work was to check the technical performance of the BTRS with features as the correct distribution of the percolate, the capacity of the percolate to trickle through the FW in the box tank, the drainage system, the effect of physical impurities and the extent of anaerobic digestion process to reach high cumulative methane yields. In this sense, no technical problems were observed during BTRS operation. Despite liquid manure has been suggested as an unsuitable inoculum source 
in dry batch anaerobic digestion because of its high viscosity (Kusch et al., 2011), the liquid inoculum used provided a successful operation, as previously reported by Qian et al. (2016) and Rico et al. (2015).

The only incidence was the blockage of the gas line in the percolate tanks after 25 days of operation. The percolate tanks were totally filled with liquid and the percolate reached the biogas line, blocking it. To solve this and continue with the BTRS operation, $1.5 \mathrm{~L}$ of percolate were removed from each percolate tank on day 25. It can be said that the purge of $1.5 \mathrm{~L}$ of percolate did not affect the process because the daily methane yield values remained in similar values to those previously yielded before the purge of the percolate. On the other hand, the impurities originally present in the FW, recovered in the digestate (Fig. 5d), did not create any operational problem as solid feedstock was confined in the box compartment.

Given that to provide a constant biogas production with this anaerobic reactor system several box compartments operated in parallel are required, a simulation has been performed with the results obtained in R1 for methane production. Despite the process has shown potential to be improved with a better percolate recirculation strategy, the simulation has been done for 30 days of retention time (RT) per batch. After 30 days the methane yield for R1 was 402, which is $84 \%$ of the methane yield reached after 47 days. The simulation consists of 6 box compartments and one percolate tank. In this simulation, each box will have a RT of 30 days and the time interval between two digesters is 5 days. Because parallel operation implies that all the box compartments are at different stages of the anaerobic process, the size of the percolate tank can be equivalent to three-fold the current percolate tank. Thus, global BTRS installation would consist of: 6 box compartments (15 L of useful volume each), 1 percolate tank 
(30 L of useful volume), and a mass flow rate of $2 \mathrm{~kg} \mathrm{~d}^{-1}$ of FW (6 box operation per 30 days). The simulated daily methane production is shown in Fig. 5c. The mean daily methane yield for the steady-state operation is $120 \mathrm{~L} \mathrm{CH}_{4} \mathrm{~d}^{-1}$. Using the useful volume of the box compartments and the percolate tank, the organic loading rate (OLR) would be $2.5 \mathrm{~kg} \mathrm{VS} \mathrm{m}^{-3} \mathrm{~d}^{-1}$ and the volumetric methane production rate (VMPR) would be 1.0 $\mathrm{m}^{3} \mathrm{CH}_{4} \mathrm{~m}^{3} \mathrm{~d}^{-1}$.

The results can be compared with a wet process for FW with similar characteristics. Edwiges et al. (2018) reported an OLR of $3 \mathrm{~kg} \mathrm{VS} \mathrm{m}^{-3} \mathrm{~d}^{-1}$ and a VMPR of $1.3 \mathrm{~m}^{3} \mathrm{CH}_{4}$ $\mathrm{m}^{3} \mathrm{~d}^{-1}$ as the best operating conditions for fruit and vegetable waste wet anaerobic digestion. Despite the wet digestion process is favourable in terms of OLR and VMPR, the BTRS has demonstrated the potential to be improved with a better percolate recirculation strategy. Additional research is necessary to get the best operating conditions in terms of inoculum to substrate ratio and percolate recirculation strategy.

\section{Conclusions}

The BTRS system with liquid inoculum has been proved as a suitable technology for the anaerobic digestion of food waste. The BTRS process did not require any previous treatment to remove physical impurities in the feedstock as it has demonstrated the capacity to process food waste with the presence of impurities. Inoculum acclimation promoted a fast start-up and allowed successful operation of the process with peaks in volatile fatty acid concentration as high as $40 \mathrm{~g} \mathrm{COD}_{\mathrm{VFA}} \mathrm{L}^{-1}$. The key role of percolate recirculation strategy has been noted. The results obtained evidenced that the process can be optimized by adjusting the percolate recirculation rate in order to reach the highest methane yield within the lower operation time. Low percolate recirculation rate 
must be applied at the start-up of the process and increased as the process progresses.

The VFA concentration in the percolate, the $\mathrm{pH}$ and the daily methane yield are relevant parameters that can be used as a signal for correct decision-making on the percolate recirculation strategy.

\section{Acknowledgements}

This research was financially supported by the University of Cantabria, the Society for the Regional Development of Cantabria (SODERCAN) and the FEDER Operational Programme for Cantabria. 


\section{References}

Algapani, D.E., Qiao, W., Su, M., di Pumpo, F., Wandera, S.M., Adani, F., Dong, R., 2016. Bio-hydrolysis and bio-hydrogen production from food waste by thermophilic and hyperthermophilic anaerobic process. Bioresour. Technol. 216, 768-777. https://doi.org/10.1016/j.biortech.2016.06.016.

André, L., Pauss, A., Ribeiro, T., 2018. Solid anaerobic digestion: State-of-art, scientific and technological hurdles. Bioresour. Technol. 247, 1027-1037. https://doi.org/10.1016/j.biortech.2017.09.003.

Angelidaki, I., Ahring, B.K., 1993. Thermophilic anaerobic digestion of livestock waste: the effect of ammonia. Appl. Microbiol. Microtechnol. 38(4), 560-564. https://doi.org/10.1007/BF00242955.

Angelonidi, E., Smith, S.R., 2015. A comparison of wet and dry anaerobic digestion processes for the treatment of municipal solid waste and food waste. Water Environ. J. 29(4), 549-557. https://doi.org/10.1111/wej.12130.

APHA, 1998. Standard Methods for the Examination of Water and Wastewater, $20^{\text {th }}$ ed. American Public Health Association, Washington, USA.

Ariunbaatar, J., Di Perta, E.S., Panico, A., Frunzo, L., Esposito, G., Lens, P.N.L., Pirozzi, F., 2015. Effect of ammoniacal nitrogen on one-stage and two-stage anaerobic digestion of food waste. Waste Manage. 38, 388-398. https://doi.org/10.1016/j.wasman.2014.12.001. 
Aymerich, E., Esteban-Gutiérrez, M., Sancho, L., 2013. Analysis of the stability of high-solids anaerobic digestion of agro-industrial waste and sewage sludge. Bioresour. Technol. 144, 107-114. https://doi.org/10.1016/j.biortech.2013.06.074.

Bong, C.P.C., Lim, L.Y., C.T., Lee, Kleme, J.J., Ho, C.S., Ho, W.S., 2018. The characterisation and treatment of food waste for improvement of biogas production during anaerobic digestion - A review. J. Clean. Prod. 172, 1545-1558. https://doi.org/10.1016/j.jclepro.2017.10.199.

Braguglia, C.M., Gallipoli, A., Gianico, A., Pagliaccia, P., 2018. Anaerobic bioconversion of food waste into energy: A critical review. Bioresour. Technol. 248, 37-56. https://doi.org/10.1016/j.biortech.2017.06.145.

Browne, J.D., Murphy, J.D., 2013. Assessment of the resource associated with biomethane from food waste. Appl. Energy 104, 170-177. https://doi.org/10.1016/j.apenergy.2012.11.017.

Brunklaus, B., Rex, E., Carlsson, E., Berlin, J., 2018. The future of Swedish food waste: An environmental assessment of existing and prospective valorization techniques. J. Clean. Prod. 202, 1-10. https://doi.org/10.1016/j.jclepro.2018.07.240.

Capson-Tojo, G., Rouez, M., Crest, M., Steyer, J.P., Delgenès, J.P., Escudié, R., 2016. Food waste valorization via anaerobic processes: a review. Rev. Environ. Sci. Biotechnol. 15(3), 499-547. https://doi.org/10.1007/s11157-016-9405-y.

Chanakya, H.N., Venkatsubramaniyam, R., Modak, J., 1997. Fermentation and methanogenic characteristics of leafy biomass feedstocks in a solid phase biogas 
fermentor. Bioresour. Technol. 62, 71-78. https://doi.org/10.1016/S09608524(97)00139-9.

Chen, Y., Cheng, J.J., Creamer, K.S., 2008. Inhibition of anaerobic digestion process: a review. Bioresour. Technol. 99, 4044-4064. https://doi.org/10.1016/j.biortech.2007.01.057.

Chiumenti, A., da Borso, F., Limina, S., 2018. Dry anaerobic digestion of cow manure and agricultural products in a full-scale plant: Efficiency and comparison with wet fermentation. Waste Manage. 71, 704-710. https://doi.org/10.1016/j.wasman.2017.03.046.

Council Directive 1999/31/EC of 26 April 1999 on the Landfill of Waste. Official Journal of the European Union, EU.

Degueurce, A., Trémier, A., Peu, P., 2016. Dynamic effect of leachate recirculation on batch mode solid state anaerobic digestion: Influence of recirculated volume, leachate to substrate ratio and recirculation periodicity. Bioresour. Technol. 216, 553-561. https://doi.org/10.1016/j.biortech.2016.05.113.

Di Maria, F., Sordi, A., Micale, C., 2012. Optimization of Solid State Anaerobic Digestion by inoculum recirculation: The case of an existing Mechanical Biological Treatment plant. Appl. Energy 97, 462-469. https://doi.org/10.1016/j.apenergy.2011.12.093.

Di Maria, F., Barratta, M., Bianconi, F., Placidi, P., Passeri, D., 2017. Solid anaerobic digestion batch with liquid digestate recirculation and wet anaerobic digestion of 
organic waste: Comparison of system performances and identification of microbial guilds. Waste Manage. 59, 172-180. https://doi.org/10.1016/j.wasman.2016.10.039.

Edwiges, T., Mantovani Frare, L., Lima Alino, J.H., Mi Triolo, J., Flotats, X., Silva de Mendonça Costa, M.S., 2018. Methane potential of fruit and vegetable waste: an evaluation of the semi-continuous anaerobic mono-digestion. Environ. Technol. 2018. https://doi.org/10.1080/09593330.2018.1515262.

Fisgativa, H., Tremier, A., Dabert, P., 2016. Characterizing the variability of food waste quality: a need for efficient valorization through anaerobic digestion. Waste Manage. 50, 264-274. https://doi.org/10.1016/j.wasman.2016.01.041.

Hawkes, F.R., Dinsdale, R., Hawkes, D.L., Hussy, I., 2002. Sustainable fermentative hydrogen production: challenges for process optimisation. Int. J. Hydrogen Energy 27(11-12), 1339-1347. https://doi.org/10.1016/S0360-3199(02)00090-3.

Jank, A., Müller, W., Waldhuber, S., Gerke, F., Ebner, C., Bockreis, A., 2017. Hydrocyclones for the separation of impurities in pretreated biowaste. Waste Manage. 64, 12-19. https://doi.org/10.1016/j.wasman.2017.03.001.

Jiang, Y., Dennehy, C., Lawlor, P.G., Hu, Z., McCabe, M., Cormican, P., Zhan, X., Gardiner, G.E., 2018. Inhibition of volatile fatty acids on methane production kinetics during dry co-digestion of food waste and pig manure. Waste Manage. 79, 302-311. https://doi.org/10.1016/j.wasman.2018.07.049.

Koido, K., Takeuchi, H., Hasegawa, T., 2018. Life cycle environmental and economic analysis of regional-scale food-waste biogas production with digestate nutrient 
management for fig fertilization. J. Clean. Prod. 190, 552-562. https://doi.org/10.1016/j.jclepro.2018.04.165

Kusch, S., Schäfer, W., Kranert, M., 2011. Dry digestion of organic residues. In: Kumar S, editor. Integrated Waste Management, Volume I, London: Intech Open; 2011, p. 155-133. https://www.intechopen.com/books/integrated-waste-management-volumei/dry-digestion-of-organic-residues.

Kusch, S., 2012. Effect of various leachate recirculation strategies on batch anaerobic digestion of solid substrates. Int. J. Environ. Waste Manage. 9, 69-88. https://doi.org/10.1504/IJEWM.2012.044161.

Li, W., Loh, K.C., Zhang, J., Tong, Y.W., Dai, Y., 2018. Two-stage anaerobic digestion of food waste and horticultural waste in high-solid system. Appl. Energy 209, 400408. https://doi.org/10.1016/j.apenergy.2017.05.042.

Morone, P., Koutinas, A., Gathergood, N., Arshadi, M., Matharu, A., 2019. Food waste: Challenges and opportunities for enhancing the emerging bio-economy. J. Clean. Prod. 221, 10-16. https://doi.org/10.1016/j.jclepro.2019.02.258.

Pognani, M., D’Imporzano, G., Minetti, C., Scotti, S., Adani, F., 2015. Optimization of solid state anaerobic digestion of the OFMSW by digestate recirculation: A new approach. Waste Manage. 35, 111-118. https://doi.org/10.1016/j.wasman.2014.09.009.

Qian, M.Y., Li, R.H., Li, J., Wedwitschka, H., Nelles, M., Stinner, W., Zhou, H.J., 2016. Industrial scale garage-type dry fermentation of municipal solid waste to 
biogas. Bioresour. Technol. 217, 82-89.

https://doi.org/10.1016/j.biortech.2016.02.076.

Qian, M., Zhang, Y., Li, R., Nelles, M., Stinner, W., Li, Y., 2017. Effects of Percolate Recirculation on Dry Anaerobic Co-digestion of Organic Fraction of Municipal Solid Waste and Corn Straw. Energy Fuels 31, 12183-12191.

https://doi.org/10.1021/acs.energyfuels.7b01869.

Reinelt, T., Delre, A., Westerkamp, T., Holmgren, M.A., Liebetrau, J., Scheutz, C., 2017. Comparative use of different emission measurement approaches to determine methane emissions from a biogas plant. Waste Manage. 68, 173-185. https://doi.org/10.1016/j.wasman.2017.05.053.

Rico, C., Montes, J.A., Muñoz, N., Rico, J.L., 2015. Thermophilic anaerobic digestion of the screened solid fraction of dairy manure in a solid-phase percolating reactor system. J. Clean. Prod. 102, 512-520. https://doi.org/10.1016/j.jclepro.2015.04.101.

Schanes, K., Dobernig, K., Gözet, B., 2018. Food waste matters - A systematic review of household food waste practices and their policy implications. J. Clean. Prod. 182, 978-991.

Scherhaufer, S., Moates, G., Hartikainen, H., Waldron, K., Obersteiner, G., 2018. Environmental impacts of food waste in Europe. Waste Manage. 77, 98-113. https://doi.org/10.1016/j.wasman.2018.04.038.

Shen, F., Yuan, H., Pang, Y., Chen, S., Zhu, B., Zou, D., Liu, Y., Mac, J., Yu, L., Li, X., 2013. Performances of anaerobic co-digestion of fruit \& vegetable waste (FVW) and 
food waste (FW): Single-phase vs. two-phase. Bioresour, Technol, 144, 80-85. https://doi.org/10.1016/j.biortech.2013.06.099.

Vavilin, V.A., Rytov, S.V., Pavlostathis, S.G., Jokela, J., Rintala, J., 2003. A distributed model of solid waste anaerobic digestion: Sensitivity analysis. Water Sci. Technol. 48(4), 147-154. https://doi.org/10.2166/wst.2003.0241.

Ventura, J.R.S., Lee, J., Jahng, D., 2014. A comparative study on the alternating mesophilic and thermophilic two-stage anaerobic digestion of food waste. J. Environ. Sci. 26, 1274-1283. https://doi.org/10.1016/j.jclepro.2017.10.199.

Xu, S.Y., Karthikeyan, O.P., Selvam, A., Wong, J.W.C., 2012. Effect of inoculum to substrate ratio on the hydrolysis and acidification of food waste in leach bed reactor. Bioresour. Technol. 126, 425-430. https://doi.org/10.1016/j.biortech.2011.12.059.

Yang, Y., Bao, W., Xie, G.H., 2019. Estimate of restaurant food waste and its biogas production potential in China. J. Clean Prod. 211, 309-320. https://doi.org/10.1016/j.jclepro.2018.11.160.

Zhang, C., Su, H., Tan, T., 2013. Batch and semi-continuous anaerobic digestion of food waste in a dual solid-liquid system. Bioresour. Technol. 145, 10-16. https://doi.org/10.1016/j.biortech.2013.03.030.

Zhang, W., Wu, S., Guo, J., Zhou, J., Dong, R., 2015. Performance and kinetic evaluation of semi-continuously fed anaerobic digesters treating food waste: Role of trace elements. Bioresour. Technol. 178, 297-305. https://doi.org/10.1016/j.biortech.2014.08.046. 


\section{Figure captions}

Figure 1. Experimental set-up scheme of the box-type reactor system.

Figure 2. Evolution of digestion parameters through inoculum acclimation stage: a) Cumulative biogas and methane production; b) Specific daily biogas and methane yield; c) volatile fatty acids; d) $\mathrm{pH}$ and alkalinity.

Figure 3. BTRS operation for R1 and R2: a) cumulative methane production in box compartment, percolate tank and overall in R1; b) cumulative methane production in box compartment, percolate tank and overall in R2; c) Methane content in biogas in box compartment, percolate tank and overall in R1; d) Methane content in biogas in box compartment, percolate tank and overall in R2; e) Daily methane yield in box compartment, percolate tank and overall in R1; f) Daily methane yield in box compartment, percolate tank and overall in R2.

Figure 4. BTRS operation for R1 and R2: a) Volatile fatty acids in percolate R1; b) Volatile fatty acids in percolate R2; c) pH, alkalinity and TAN in percolate $\mathrm{R} 1$; d) $\mathrm{pH}$, alkalinity and TAN in percolate R2.

Figure 5. a) Daily methane yield comparison for R1 and R2; b) Percentage contribution to cumulative methane yield in five-day cycles for R1 and R2; c) Simulated daily methane yield in a 6-box BTRS system; d) physical impurities found in the digestate after BTRS operation. 